\title{
Percepção de professores coordenadores de área e supervisores sobre ações e contribuições do Pibid Biologia em seu processo formativo
}

\section{The perception of area coordinator-teachers and supervisors on actions and contributions of Biology IPTIS for teacher education}

Alexsandro Alberto da Silva

Monica Lopes Folena Araújo

\begin{abstract}
Universidade Federal Rural de Pernambuco (UFRPE), Recife, PE, Brasil. Autor correspondente: alexsandro.asilva@ufrpe.br
\end{abstract}

Resumo: A formação continuada se dá pela construção de conhecimentos didáticopedagógicos que possibilitam o exercício da docência. No entanto, muitas vezes, são pouco valorizados no processo formativo e na vivência, principalmente, dos supervisores vinculados ao Programa Institucional de Bolsas de Iniciação à Docência (Pibid) no chão das escolas. Nesta perspectiva, este estudo objetivou analisar concepções de professores coordenadores e supervisores do Pibid Biologia acerca das ações e contribuições em seu processo formativo. A partir da análise de entrevistas realizadas é possível inferir que o Pibid desempenhou importante papel na formação de uma identidade profissional docente, pois proporciona aos coordenadores e supervisores uma reflexão sobre o verdadeiro papel do professor reflexivo-investigativo, graças à troca entre escola e universidade. O programa contribuiu para a formação de professores, possibilitando a criação de oportunidades de vivência da prática docente baseada na reflexão crítica das suas próprias ações.

Palavras-chave: Ensino de biologia; Formação continuada do professor; Pibid; Identidade profissional; Prática docente.

Abstract: Continuing education takes place through the construction of didacticpedagogical knowledge, which enables the exercise of teaching; however, it is often undervalued in the education of and in the experience, mainly, of supervisors linked to the Institutional Program of Teaching Initiation Scholarships (IPTIS) in schools. In this perspective, this study aimed to analyze conceptions of teacher coordinators and supervisors of Biology IPTIS on actions and contributions for teacher education. Based on the analysis of interviews it is possible to infer that the IPTIS played an important role in the formation of a teaching professional's identity, because it provides coordinators and supervisors with a reflection about the true role of the reflective-investigative teacher thanks to the schooluniversity interaction. The program contributed to the training of teachers, allowing for the creation of opportunities for living the teaching practice based on the critical reflection on their own actions.

Keywords: Biology teaching; continuing teacher training; IPTIS; Professional identity. Teaching practice. 


\section{Introdução}

Os programas de formação de professores da educação brasileira vêm ainda apresentando problemáticas relacionadas à dicotomia teoria-prática, ou seja, no sentido de promover a construção de saberes culturais da realidade com aqueles adquiridos na formação inicial e na prática pedagógica. Isso implica em um processo formativo pouco significativo para uma epistemologia da práxis no exercício da docência. Além disso, as mudanças ocorridas no cenário educacional, nos últimos anos, como a inovação científica e tecnológica, vêm suscitando a ressignificação do papel do educador e das fragilidades presentes na profissionalização de professores (DANTAS et al., 2016).

Quando falamos de formação continuada de professores também encontramos no bojo de suas vivências modelos de atividades pedagógicas prontas para serem reproduzidas em sala de aula, sem levar em consideração os contextos específicos das naturezas-culturas de cada espaço educativo a fim de incorporá-los como um saber vivo e ativo (BARCELOS; VILLANI, 2006). Outro ponto destacado por Cunha e Krasilchick (2000) é o não reconhecimento de que os professores têm muito a contribuir e não só a aprender quando se trata de formação continuada, visto que é necessário que sua formação aconteça no exercício do cotidiano escolar de forma constante e contínua.

Entretanto, diante do contexto apresentado, é inegável que a formação, qualificação e a capacitação dos professores sejam indispensáveis para um ensino de qualidade. Segundo Maldaner (2000, p. 391), "[...] a formação continuada é inerente ao exercício profissional do professor, de complexidade crescente. A ideia de professor/ pesquisador, que cria/recria sua profissão no contexto da prática [...] permite superar as formas tradicionais de treinamento em serviço".

É nesse entorno que o viés formativo na práxis se configura como uma das temáticas centrais no cenário educacional. Nesse sentido, novos olhares e perspectivas ganham destaque, a saber: a importância, a reflexão e os saberes da prática do-discente. Pesquisadores como Schön, Zeichner, Nóvoa, Alarcão e outros apresentam reflexões que subsidiam essa nova visão de fomentar e vivenciar a formação profissional de professor enquanto uma ação processual, reflexiva e crítico-investigativa no e sobre o contexto em que se insere o ato educativo e não pelo simples acúmulo de saberes desarticulados das experiências das práticas culturais.

Desta forma, os debates sobre a formação docente na educação básica e superior continuamente têm sido um grande desafio para os atores envolvidos com a atividade pedagógica, devido à deficiência do campo da educação vivenciada em nosso país, como preconiza os documentos oficiais, leis e resoluções (BORGES; DANTAS, 2015). Doravante, essas questões evidenciam o crescente interesse em pesquisas com foco na formação inicial e continuada de professores (CUNHA; KRASILCHIK, 2000).

Para Dantas et al. (2016) as formações continuadas emergem da necessidade de suprir as lacunas deixadas pela formação inicial. Sobre isso, acreditamos que a formação primária na graduação não deva dar conta de todo o espectro necessário à identidade docente, pois é consenso na comunidade científica que o processo formativo não se finda neste momento de saber-fazer docente. Contudo, deveras, corroboramos com os autores que as licenciaturas não promovem um desempenho necessário à atuação do educador nos espaços formativos. 
Gatti (2008) elencou duas dimensões relacionadas à formação continuada: a primeira, restrita aos cursos estruturados e formalizados oferecidos após a graduação (ou após o ingresso no magistério); e a segunda, sendo as atividades vivenciadas pelo educador, principalmente, no chão da escola ou na própria busca, uma vez que visam contribuir para o desenvolvimento profissional a fim de promover reflexões e a reorientação de seu fazer pedagógico.

Não obstante, encontra-se ainda no cerne das discussões apontadas por pesquisadores em educação em ciências, a falta de integração entre universidades e escolas, os estudos teóricos e a prática docente como uma das causas da ineficiência na formação de professores (CUNHA; KRASILCHIK, 2000). Portanto, cursos de formação continuada têm o papel, entre nós, não só de garantir a atualização dos professores, como também de suprir deficiências dos cursos de formação inicial. E, ainda, incrementar as tendências pedagógicas inovadoras, criativas e ativas.

Lück (2009, p. 78) nos lembra que "[...] a integração da escola com a comunidade e com os pais tem sido identificada como um fator importantíssimo para o bom funcionamento da escola e qualidade de seu processo educacional". Portanto, é de extrema importância a inserção da escola em projetos que a universidade oferece, pois as vivências e experiências adquiridas contribuem muito para a formação.

Baird et al. (1991) destacaram, desde a década de 1990, que os cursos de aperfeiçoamento para professores devem preocupar-se com o desenvolvimento de competências e atribuições baseadas em tarefas e com o desenvolvimento de elementos voltados ao cognitivo e desempenho, como consciência de si e dos objetivos educacionais. Krasilchik (1987) apontou também quais condições aumentam o êxito dos cursos de aperfeiçoamento de professores, a saber: a participação voluntária, a existência de material de apoio, a coerência e a integração conteúdo-metodologia. A autora destaca sobre a importância de esses cursos atenderem grupos de professores de uma mesma instituição de ensino.

Segundo Cunha e Krasilchik (2000), alguns pontos devem ser levados em consideração em relação ao aperfeiçoamento de professores, tais como: evitar turmas muito heterogêneas; manter a continuidade dos cursos de aperfeiçoamento; o envolvimento do professor para potencializar as mudanças; o trabalho em grupo como elemento fundamental; os professores devem se tornar conscientes das suas concepções, refletindo acerca delas na sua própria prática, a fim de identificar os pressupostos epistemológicos subjacentes a ela.

Todos os estudos divulgados sobre formação de professores vêm colaborando com a proposição de políticas e programas que possam potencializar o processo formativo, tanto o inicial quanto o continuado. Neste cenário, o Programa Institucional de Bolsas de Iniciação à Docência (Pibid) é um programa educativo criado com o intuito de contribuir com a formação de professores (inicial e continuada), em todas as áreas, por meio da concessão de bolsas para estudantes das licenciaturas, articulando a relação entre a universidade e a escola. Este programa é financiado e idealizado pela Coordenação de Aperfeiçoamento de Pessoal de Nível Superior (CAPES) de acordo com a Portaria $n^{\circ} 260$, de 30 de outubro de 2010. O programa contribui para a formação continuada dos professores em exercício profissional e estímulo ao professor universitário (BRASIL, 2010). 
O Pibid apresentado nesse estudo teve início em 2009 e, desde então, trabalha em prol da formação inicial de professores das licenciaturas ofertadas por uma universidade pública federal, por meio do aprofundamento teórico em relação aos elementos fundantes da formação e do saber-fazer docente. Dessa forma, a interação entre os saberes da universidade e os da escola podem contribuir para a melhoria do processo de ensino e aprendizagem dos professores iniciantes e daqueles em exercício nas escolas envolvidas, os supervisores, como também os coordenadores.

No estudo de Santos, Soares e Scheid (2015) foram apresentados resultados significativos do projeto Pibid, com contribuições para a formação inicial e continuada de professores e para o ensino de Ciências/Biologia nas instituições de ensino vinculadas, uma vez que os graduandos "[...] tiveram a oportunidade de conhecer o seu cotidiano, de planejar e aplicar diversas modalidades didáticas e de realizar reflexões sobre a relação teoria/prática durante atividades desenvolvidas nas escolascampo" (SANTOS; SOARES; SCHEID, 2015, p. 171). Os autores ainda discorreram sobre a importância do Pibid na qualificação dos professores supervisores.

Na pesquisa de Santos (2016) encontramos também contribuições do Pibid na formação continuada de professores de Ciências/Biologia, tais como a renovação do interesse e desejo pela profissão, o favorecimento de mudanças na prática docente, a demonstração de uma ação mais reflexiva, reorientando a visão do fazer profissional, assim como "[...] a adoção de novas metodologias e práticas que passaram a integrar suas ações docentes" (SANTOS, 2016, p. 7).

A literatura mostra também que o Pibid traz benefícios para a universidade e para a escola, mas nos perguntamos: qual é a percepção dos professores coordenadores de área e supervisores quanto à influência das ações e contribuições do Pibid Biologia em seu processo formativo? Tendo este problema como norteador, apresenta-se o objetivo da pesquisa: analisar a percepção de professores supervisores e coordenadores de área do Pibid Biologia sobre os impactos das ações e contribuições em seu processo de formação continuada.

\section{Metodologia}

A abordagem de pesquisa foi de natureza qualitativa, com método descritivo, conforme Oliveira (2012). Os atores sociais envolvidos foram supervisores e orientadores do Pibid Biologia de uma Instituição de Ensino Superior (IES) pública federal do Brasil. Somente serão apresentados dados de quatro entrevistados (incluindo uma coordenadora e três supervisores). Embora sete membros do programa tenham sido abordados e convidados para a participação na pesquisa, apenas estes se dispuseram. As entrevistas dos supervisores foram realizadas nas escolas-campo das quais pertenciam e da coordenação, em sua sala na IES.

Ao esclarecer para os entrevistados os objetivos da pesquisa, deixou-se claro a segurança do anonimato, conforme orientações de documentos de ética nas pesquisas com seres humanos. No caso desse estudo, não havia um comitê de ética constituído na universidade de origem dos pesquisadores, por isso, foi solicitado aos participantes que assinassem um Termo de Livre Esclarecimento e Consentimento para que suas falas pudessem ser explicitadas. Diante disso, os atores sociais da pesquisa são identificados por letras maiúsculas: 'A', 'B', 'C' e 'D'. Para a coleta de dados, usou-se a técnica de roteiro de entrevistas por permitir, dentre outras, uma maior interação 
entre duas ou mais pessoas com um propósito diferente da mera conversação, pois nela se valoriza o uso da palavra, símbolo e signo devido ao seu valor para as relações comunicativas (FRASER; GONDIM, 2004). E, conforme Gil (2002), define-se por semiestruturada, haja vista permitir que ela seja conduzida por focos de interesse do pesquisador no desenrolar de sua aplicação.

Nesse sentido, foi utilizado um roteiro de entrevista composto por doze questões norteadoras, passíveis de serem acrescidas outras perguntas a depender da resposta apresentada pelo(a) entrevistado(a), de modo a alcançarmos o objetivo delineado nesta pesquisa. As entrevistas foram realizadas entre os meses de novembro de 2017 e fevereiro de 2018 em gravações de áudio, por meio de um aplicativo de telefonia móvel e, posteriormente, transcritas.

A análise foi feita seguindo-se premissas da análise de conteúdo (BARDIN, 2011), a saber: primeiro, a fase pré-exploratória do material ou de leituras flutuantes do conteúdo das entrevistas; segundo, a seleção das unidades de análise ou unidades de sentidos temáticos; terceiro, os processos de categorização e subcategorização, emergidos das entrevistas pela frequência de conteúdos comuns aos respondentes, atrelados ao processo de codificação das unidades de análise. Sendo assim, foram definidos dois eixos temáticos: ações desenvolvidas no âmbito do Pibid Biologia e contribuições do Pibid Biologia para a atuação e formação docente.

\section{Questões norteadoras da entrevista}

1. Sinalize as contribuições do Pibid no trabalho coletivo desenvolvido. Exemplifique.

2. Sinalize as contribuições do Pibid para as aprendizagens possíveis no âmbito do Pibid.

3. Houve contribuições do Pibid em relação à apresentação de trabalho em eventos? De que forma?

4. Houve contribuições do Pibid quanto à manipulação de instrumentos para a docência e à investigação educacional? De que forma?

5. Houve contribuições do Pibid para produção de conhecimento e saberes sobre docência e a escola? De que forma?

6. Houve contribuições do Pibid em produções didático-pedagógicas? Como?

7. Houve contribuições do Pibid em produções bibliográficas? Quais?

8. Houve contribuições do Pibid em produções artístico-culturais? Quais?

9. Houve contribuições do Pibid em produções desportivas? Como?

10. Houve contribuições do Pibid em atividades lúdicas e técnicas? Quais?

11. Houve contribuições do Pibid na manutenção de infraestrutura? Como?

12. O Pibid contribuiu para sua formação e para melhor exercício da docência? Como?

\section{Resultados e discussão}

Pelo explicitado nas questões norteadoras da entrevista, dos eixos temáticos emergiram subtemáticas, tais como o trabalho coletivo desenvolvido, as aprendizagens possíveis, a apresentação de trabalho em eventos, a manipulação de instrumentos para a docência e a investigação educacional, a produção de conhecimentos e saberes 
sobre a docência e a escola; produções didático-pedagógicas, bibliográficas, artísticoculturais, desportivas, lúdicas, técnicas e de manutenção de infraestrutura.

\title{
Ações desenvolvidas no âmbito do Pibid Biologia
}

Em relação ao trabalho coletivo desenvolvido é possível verificar que houve contribuições, com os seguintes depoimentos:

\begin{abstract}
Nós atuamos como uma coordenação colegiada e dentro desta coordenação colegiada nós temos um trabalho coletivo, pois todo mundo acabou comprando essa ideia de que todos os coordenadores de área são responsáveis por todo o programa. Então, todas as decisões são tomadas coletivamente. [...] [A].
\end{abstract}

Acho que o Pibid ajuda porque quando o trabalho é multidisciplinar os Pibidianos se ajudam. [B].

Primeiramente, os bolsistas chegaram na escola e todo o trabalho coletivo que chega com essa vontade, essa sede de realização, sempre traz algo positivo para a gente. Então, temos uma equipe, onde chegou a equipe do Pibid, trazendo uma proposta para fazer tudo de novo inovador. Então, eles viram coisas que passavam despercebidos por nós. E nos alertavam. [C].

Com o Pibid, ficou mais fácil os trabalhos interdisciplinares. [D].

As respostas dos entrevistados indicam que no Pibid da instituição estudada há um trabalho colaborativo entre pibidianos, coordenadores e supervisores, na perspectiva de construção de saberes compartilhados de suas experiências formativas. Isso se torna a característica essencial oriunda desse ato, a participação e a vivência de um processo coletivo de reflexão sobre as questões do cotidiano escolar, os quais possibilitam a articulação de conhecimentos teóricos à prática escolar por intermédio do compromisso firmado entre os participantes. Santos, Soares e Scheid (2015) também evidenciaram a importância dessa interação e troca de saberes experienciais entre os Pibidianos e os professores supervisores, favorecendo uma maior reflexão sobre as dificuldades oriundas das atividades realizadas no chão das escolas.

Os referidos autores apontaram para o crescimento profissional e pessoal mútuo (supervisor e licenciando) por meio das trocas de experiências. A interação escolaestudantes-professores-supervisores trouxe a percepção de entender a docência como uma atividade coletiva, porque é na heterogeneidade e nas situações vividas que se tem a necessidade do diálogo e da troca com os demais sujeitos envolvidos para tornar os processos de ensino e aprendizagem mais significativos (BORGES; DANTAS, 2015).

Essa ideia se ratifica fortemente na fala do supervisor $D$, quando relacionou a ajuda dos Pibidianos nos trabalhos interdisciplinares, uma vez que a natureza dessa ação motiva o diálogo com outros saberes, a fim de buscar soluções comuns dos problemas apresentados no contexto escolar em estudo. Dessa forma, promover atuações educativas coletivamente exige do profissional um maior aprofundamento, com pesquisa e diálogo com outras ideias, emergidas, inclusive, pelos próprios Pibidianos, ao trazerem novas possibilidades teórico-metodológicas do saber acadêmico.

Quando questionados a respeito das possíveis aprendizagens, os entrevistados responderam: 
Dentro do Pibid são muitas aprendizagens. Isso é uma coisa muito boa porque traz outras aprendizagens. [...] Estudante que daqui a pouco vai estar atuando na escola, então eu aprendo muito com os meninos, os bolsistas. E outra aprendizagem que o Pibid me traz é a aprendizagem do contato com a escola pública, com a educação básica. [A].

O que me ajudou nestes oito anos que eu estou como supervisora do Pibid é essa questão de a gente se renovar. [...] E o aluno ver, por exemplo, como futuro professor que está em formação, essa relação entre o professor e o aluno da escola. A troca entre professores e bolsistas. [B].

Principalmente a questão do trabalho em grupo, porque eu acho que quando a gente tem os Pibidianos, a Coordenação Geral e os supervisores, ou se caminha de uma forma alinhada ou as coisas não acontecem. Então, esse entrosamento foi bastante positivo para a escola. [C].

É possível ver como é a prática cotidiana do professor. [D].

É possível perceber aprendizados das participações deles no Pibid, corroborando Borges e Dantas (2015), que dizem que para o coordenador/supervisor, o Pibid é também uma possibilidade para a formação continuada, visto que nos estudos com a equipe acadêmica, ele retoma suas leituras teórico-metodológicas, reflete sobre sua prática em um movimento de ação-reflexão-ação com vistas ao aperfeiçoamento. Desse modo, o professor acaba não ocupando posição passiva, mas sendo sujeito reflexivo-investigador de sua prática.

Santos (2016) argumentou que o processo formativo não se acaba para o docente com a conclusão da graduação a fim de que este esteja apto para o exercício profissional com competência. Dessa forma, a autora aponta sobre a importância de a formação continuada estar pautada na vivência das diversas situações e dificuldades do cotidiano da escola.

Para Tardif (2007), a falta de conhecimentos práticos causa entraves ao professor quando inicia sua atividade profissional, uma vez que a formação docente ainda é muito ligada ao modelo de ensino de disciplinas e teorias, o qual não traduz relação com a realidade diária da prática docente e suas singularidades. Como chamam Garcia e Porlán (2000) de modelo baseado na primazia do saber acadêmico, onde o único saber relevante é o disciplinar (científico e pedagógico).

Nesse contexto de discussão encontramos relações das falas dos entrevistados A e B com as categorias evidenciadas no estudo de Santos (2016), como espaços de estudos, de fortalecimento profissional, motivação para mudança, qualificação da prática docente, mudanças efetivas nas práticas dos professores, apoio ao professor, melhorias na aprendizagem dos alunos, a partir da adoção de novas práticas na escola em suas relações socioafetivas.

Esse viés sugere que a vivência dos Pibidianos com os professores supervisores promovem aprendizagens múltiplas, tanto para os professores em formação inicial quanto para àqueles em exercício, bem como ao aluno da escola-campo com propostas mais significativas que as aulas tradicionais. É nessa troca mútua de experiências, saberes e emoções que se constrói o ambiente de aprendizagem vivenciado no âmbito do Pibid.

Em relação à publicação de trabalhos em eventos como resultados do trabalho do Pibid, tem-se: 
Contribui muito para apresentação de trabalhos em eventos porque já é uma condição nossa que o bolsista do Pibid apresente pelo menos em um evento que a gente organiza anualmente que é o SID [Simpósio de Iniciação à Docência]. Mas o que eu tenho verificado de maneira mais efetiva é que os bolsistas têm publicado também em outros eventos [...]. [A].

Muitos, eu tenho vários trabalhos publicados no SID, congressos, JEPEX. [B].

Sim a participação dos Pibidianos no SID. [C].

Houve sim. Apresentaram seus projetos desenvolvidos na escola. [D].

Frison, Leite e Barcellos (2017) apontam a participação dos coordenadores e supervisores como sendo fundamental para os bolsistas, pois são eles que realizam a mediação entre universidade e escola, possibilitando o trânsito entre os espaços das escolas, mostrando as realidades de trabalho e dos currículos, ao oportunizar atuar, conviver e compreender o contexto de cada escola enquanto aprendizes de professores.

Todo esse trabalho resultou, com o estímulo da universidade, nas publicações de pesquisas e relatos de experiências em eventos. Semelhante ao apontado no trecho seguinte: "[...] os resumos e trabalhos apresentados em eventos ocorrem em parceria bolsista de iniciação à docência-professor da universidade-professor da escola e isso contradiz o movimento hegemônico da universidade ser produtora de conhecimento e a escola uma consumidora" (ARAÚJO, 2017, p. 80-81).

O envolvimento com o programa de iniciação à docência permite ao professor se incomodar com sua atuação, refletindo e reinventando-a, na medida em que essa vivência, troca de experiências, articulação e produção de saberes da ciência escolar no chão da escola, motiva-o "[...] a buscar novas estratégias de trabalho para ser exemplo positivo para os bolsistas que os estão acompanhando nas aulas" (SANTOS, 2016, p. 84). E, ainda, impulsiona o supervisor a participar desse ambiente de produção acadêmica entre a universidade e a escola.

Assim, o Pibid Biologia evidenciou diversas possibilidades para a formação docente, dentre elas, a continuidade do processo formativo, quanto à qualificação e ao aperfeiçoamento dos supervisores, já que no atual cenário, demanda um constante refazer profissional. Então, pode-se destacar, nesse estudo, o Pibid como meio de produção acadêmica dentro do contexto educacional enquanto uma subcategoria que não foi evidenciada nos estudos de Santos (2016) e Santos, Soares e Scheid (2015), ambos refletindo sobre a formação de professores e o Pibid.

Sobre a manipulação de instrumentos para a docência e à investigação educacional, os entrevistados nos disseram que:

Os bolsistas manipulam muitas coisas para exercer a docência [...] A gente sempre orienta, eles vão para escola fazer a diagnose da mesma e a partir dessa diagnose vai poder saber o que há na escola [...] $A$ partir daí eles planejam as ações. Eles acabam manuseando diferentes coisas de acordo com que aquela escola dispõe para eles [...] $E$ a investigação educacional acontece o tempo todo porque o bolsista do Pibid tem que publicar e socializar o que constrói [...] A ideia é que o bolsista seja sempre reflexivo. [A]. 
Teve quando os projetos que os bolsistas traziam, por exemplo, questionário, estou aplicando uma metodologia com determinado conteúdo. Aí vocês trazem questionário e entrevistas e a gente consegue visualizar que aquela atividade atingiu o objetivo e se o aluno compreendeu de fato a matéria repassada e mostra também o lado qualitativo e não somente o quantitativo. [B].

Sim, com produção de sabão, jogos, atividades práticas de laboratório. [C].

Houve sim. O Pibid aqui [...] contribui planejando junto com o professor as práticas de laboratório. [D].

Aqui se compreende que a investigação precede as atividades a serem desenvolvidas pelos bolsistas, pois é por meio da diagnose da escola que os instrumentos para o exercício da docência são planejados. Somente após essa etapa é que os bolsistas optam por atividades como uma oficina de produção de sabão ou atividades práticas em laboratório, por exemplo. Além de serem estimulados a socializar o que constroem e definir quais questionários e entrevistas são utilizados como forma de investigar os processos de ensino e aprendizagem.

Para Santos, Soares e Scheid (2015), a vivência de uma prática reflexiva e crítica durante a formação inicial dará suporte ao futuro professor para a construção de sua identidade docente. Nesse sentido, os momentos de trocas de novas experiências em sala de aula oferecem ao graduando e supervisor um ambiente motivador, onde poderão encontrar incentivo e motivação, assim como assimilação de novas ferramentas metodológicas para sua prática.

\section{Contribuições do Pibid Biologia para a atuação e formação docente}

Em relação às produções didático-pedagógicas, os entrevistados disseram:

Muita, os bolsistas do Pibid acabam sendo muito criativos para dar conta do dia a dia da escola $e$ geralmente os professores da escola solicitam que os nossos bolsistas tragam alguma coisa diferente para a escola. Aí os nossos bolsistas fazem maquete, jogos lúdicos, Quiz, gincana, práticas de modos diferenciados para consolidar aquele conteúdo que foi trabalhado com os estudantes de forma teórica. $[\mathrm{A}]$.

Sim, principalmente quando a gente faz monitoria e as monitorias trazem jogos, atividades lúdicas, dinâmicas, Quiz. Eu gosto muito do quiz dos meninos. Eu acho que contribui bastante. [B].

Alguns jogos, alguns materiais para ficar na escola, a revitalização do laboratório de biologia. [C].

Sim. Produziam os roteiros das aulas práticas de laboratório, também planejamento de aulas como intervenções, e projetos. [D].

Diante do exposto, identificam-se diversas contribuições didático-pedagógicas, as quais buscam direcionar os estudantes à aprendizagem de conteúdos já trabalhados teoricamente pelos professores da escola-campo de atuação dos bolsistas. Além disso, é nítido o olhar para o planejamento de aulas, quer sejam práticas, de laboratório ou de projetos pelos Pibidianos. O que nos indica a relevância do envolvimento dos licenciandos com os professores supervisores, em um movimento dinâmico de aprendizagens sobre o saber-fazer docente, no qual eles trazem os conhecimentos construídos até o momento da universidade, com criatividade, ludicidade e envolvimento, diferente do formato de alguns estágios curriculares da docência em Biologia. 
Em conformidade ao que evidenciamos, encontramos diferenças significativas quanto ao debate sobre os entraves e perspectivas do estágio docente oferecido pelas universidades. Segundo Pimenta e Lima (2006), os estágios deveriam olhar para o processo educativo a partir da análise, avaliação e crítica na estruturação de projetos e aulas interventivas frente aos desafios e dificuldades que o cotidiano da escola revela. É nesse entorno que se compreende como se vivencia o programa de iniciação à docência na proposição de projetos interventivos pautados na realidade e por meio de sua diagnose, feedback e reflexão argumentativa. Corroborando Santos (2016), ele se torna importante para a qualificação docente, promovendo mudanças efetivas na prática dos professores.

Em relação às produções bibliográficas, todos afirmaram a experiência, com exceção da entrevistada [D]:

Houve sim, além dos artigos publicados em eventos, temos alguns trabalhos publicados em periódicos. [...] Estamos lançando junto com esse livro, mais três livros: um sobre vivências, um sobre contextualização e interdisciplinaridade e o outro que traz um acúmulo de trajetórias vivenciadas no Pibid ao longo desse. $[\mathrm{A}]$.

Tivemos alguns resumos publicados. Teve também o livro do Pibid que eu contribuí com alguma escrita. [B].

Um dos Pibidianos estava fazendo um resumo para o congresso, mas também os resumos do SID. [C].

Nesse sentido, fica claro que as produções bibliográficas envolvem trabalhos submetidos em eventos, livros e artigos publicados em periódicos. Isso nos levou a inferir que a formação no Pibid Biologia contribuiu para a qualificação acadêmica dos licenciandos, supervisores e coordenadores em dois aspectos: no aprimoramento de ações de iniciação à docência, relativas à sala de aula propriamente ditas, mas também na melhoria de seus currículos acadêmicos. Aspecto não observado no estudo de Santos (2016), podendo ser apontada mais uma vez pela nossa pesquisa aquela mesma nova subcategoria da qualificação docente promovida pelo Pibid, enquanto meio de produção acadêmica, emergindo do seio da prática, da reflexão crítica, avaliativa, analítica e construtora de saberes da ciência escolar, em uma relação universidadeescola.

Quanto à produção artístico-cultural, apresenta-se:

Houve, mas não muitas. A Biologia às vezes tem interdisciplinaridade com alguém da educação física como, por exemplo, uma gincana na escola, onde muitas vezes o artístico-cultural aparecia. Já teve um teatro sobre fotossíntese, onde os estudantes de educação física trabalharam as questões corporais e os da biologia trabalharam os conteúdos específicos da fotossíntese. Então já houve, mas não é com muita frequência. [A].

Quando participamos de algumas atividades da escola, de alguns eventos. Este ano eu não vi muito envolvimento do Pibid, mas em outros anos pude perceber. [B].

Houve a participação dos bolsistas em diversos projetos nas disciplinas eletivas que ocorrem nos dias de sexta-feira, como se fossem oficinas. [...] e nessas oficinas sempre temos um produto final, por exemplo: um teatro, um documentário, dança, produção de material utilizando material reciclável. [C]. 
Sim. Participaram de forma direta do evento da Consciência Negra. Onde foram também monitores. [D].

Frente ao exposto, as produções artístico-culturais não são muito frequentes no Pibid Biologia e, quando ocorreram, estavam associadas às ações de outras áreas do programa, como foi citada a Educação Física. Assim, tais produções podem ser mais estimuladas em ações futuras, de forma disciplinar e interdisciplinar. Aspecto esse que Santos (2016) aponta como promotor da qualificação docente e repercussão na aprendizagem, haja vista acarretar mudanças efetivas na prática, sendo apoio ao professor e aprimorando a aprendizagem dos alunos.

Barbosa e Soares (2012), pesquisando sobre o Pibid, perceberam que as contribuições deste programa são para todos os envolvidos no projeto, contudo, principalmente, para que os bolsistas percebam a escola como um espaço por excelência de sua formação e construção de conhecimentos, no sentido de fomentar, junto aos professores das escolas-campos, práticas pedagógicas diversas e diferenciadas quanto às metodologias de ensino, planejamento e avaliação.

Em relação às produções desportivas os entrevistados disseram que:

Não recordo de nenhuma produção desportiva da biologia, acho que se enquadra mais com pessoal da educação física. [...] É difícil trabalhar dentro da instituição e, quando se pensa que precisamos levar para escola, nos deparamos ainda com outras barreiras. [A].

Tá mais voltado para o pessoal da educação física. [B].

Os bolsistas do Pibid participaram apenas observando os jogos da escola. [C].

Sim. Participaram dos jogos internos [...] [D].

Esses tipos de produções são mais ligados à área de Educação Física, embora a interdisciplinaridade possa servir de ponte para tais produções com a Biologia. Como destacado anteriormente, a interdisciplinaridade ainda é algo a ser melhorado no âmbito do Pibid na instituição campo de estudo, visto que ele preconiza a interdisciplinaridade e a contextualização como focos em ações colaborativas.

Outro aspecto que pode contribuir para que a interdisciplinaridade ocorra é a resistência do professor frente às mudanças quando se fala em trabalhos de natureza interdisciplinar, como relatam Rodrigues e Arena (2007), haja vista ele estar acostumado a desenvolver sozinho o seu planejamento e a aplicação de suas atividades e, possivelmente, sinta receio de críticas às suas aulas.

No que diz respeito às produções lúdicas e técnicas, a coordenadora e os professores supervisores discorreram:

A atividade lúdica tem muita. [...] Nós acabamos trabalhando com muitos jogos como eu falei, já teve jogo com zoologia, quiz de fotossíntese, têm muitas atividades com jogos. [A].

Muito. O lúdico faz parte pelo que eu vejo, principalmente na parte de biologia sempre tem um lúdico e os outros que estão trabalhando também acabam contribuindo. [B].

Houve muitos jogos, por exemplo:jogo de genética para confecção de um boneco com várias características genéticas. [C]. 
Sim. Atividades como jogos de memória, caça palavras e perguntas e resposta todos dentro do conteúdo trabalhado em sala. [D].

A ludicidade é recomendada em documentos oficiais que regem a educação básica brasileira, tais como nos Parâmetros Curriculares Nacionais (PCN) e, mais recentemente, na Base Nacional Comum Curricular (BNCC). Diante disso, depreende-se que ela se apresenta em jogos que tratam de conteúdos diversos, como a zoologia, a fotossíntese e a genética. No entanto, ainda é expressivo o uso das estratégias lúdicas como forma de avaliar a aprendizagem do conteúdo trabalhado. Por outro lado, Soares (2013, p. 184) argumenta que "[...] a ludicidade quebra algumas barreiras de poder e aproxima aprendiz e mestre", pois há diversão ao ensinar e ao aprender.

Assim, quando se fala dos processos de ensino e aprendizagem, o uso da ludicidade encontra endosso com as categorias propostas por Santos (2016), conhecidas por melhorias para a aprendizagem dos alunos a partir da adoção de novas práticas na escola, apoio ao professor, a prática docente, espaço de estudos e motivação para a mudança.

Em relação às contribuições para a manutenção de infraestrutura, eles afirmaram o seguinte:

\begin{abstract}
Algumas das escolas nas quais atuamos tinham laboratórios de ciências, mas não eram utilizadas. $E$ não eram utilizados por diversos motivos. [...] A gente se depara com aqueles laboratórios que servem biologia, física e química, perfeitos, mas os professores não sabem utilizar. [...] Muitas vezes os materiais chegam na escola (robô, computadores), mas os professores não sabem utilizá-los e aquilo vira um elefante branco. Então algumas escolas que tinham esses kits os nossos bolsistas conseguiram trabalhar realizando oficinas para os professores, para que eles pudessem passar a manusear aquele material. [A].

Sim, nós precisamos dos Pibidianos para ajudar em aplicação de prova, organização de sala, organização dos laboratórios. Que às vezes precisa de uma reorganização. O Pibid ajudou na identificação do material que tem no laboratório e na verificação do que estava faltando. Houve contribuições do Pibid no laboratório de informática, na biblioteca. [B].
\end{abstract}

Houve a revitalização do laboratório. [C].

Sim. Na manutenção de um jardim e de uma pequena horta de ervas medicinais. [D].

Nas disciplinas de Ciências e Biologia, as aulas práticas são fundamentais para facilitar o aprendizado do aluno, pois possibilitam a vivência dialética dos conteúdos construídos em uma relação teoria-prática (BEREZUK; INADA, 2010). Para os referidos autores, as aulas experimentais são essenciais para que o aluno estruture o aprendizado em diferentes cursos científicos, pois os alunos manuseiam equipamentos e presenciam fenômenos ou organismos que podem ser vistos a olho nu ou com a ajuda de microscópios. Além disso, nas aulas práticas, os alunos exercitam o raciocínio, desenvolvem outras habilidades e são estimulados ao desafio de pensar sobre aquilo que aprende.

Os argumentos trazidos pelos autores levam-nos a ressaltar a importante atuação do Pibid Biologia na manutenção e revitalização da infraestrutura de laboratórios nas escolas parceiras. Ademais, percebemos que a oferta de oficinas para os professores aprenderem a utilizar o material disponibilizado na escola tem relevante papel formativo com reflexos imediatos na educação. Sobre isso, Zeichner (2010) afirma que 
na experiência do Pibid é possível a criação de espaços híbridos nos programas de formação inicial de professores, ao reunirem-se professores da educação básica e do ensino superior, com conhecimentos práticos, profissionais e acadêmicos.

Esse movimento entre formação inicial e continuada de professores vivenciado por participantes do programa que se encontram em momentos diferentes do exercício profissional, instiga-nos a considerar a ideia da circularidade de saberes exercida no cotidiano escolar por diferentes atores (FELÍCIO, 2014).

\section{Considerações finais}

Diante do exposto, ao analisar a percepção de professores supervisores e coordenadores de área do Pibid Biologia sobre os impactos das ações e contribuições em seu processo de formação continuada, pode-se concluir que o programa tem contribuído de forma positiva na formação, não apenas dos bolsistas, mas para a formação continuada de professores, supervisores e coordenadores do programa, quanto às aprendizagens possíveis, ao trabalho coletivo desenvolvido, à produção de trabalhos apresentados em eventos, produções bibliográficas, artístico-culturais, lúdicas e técnicas realizadas para construir saberes da docência na cultura escolar. Além de permitir investigar a instrumentalização docente e a infraestrutura da escola para um melhor exercício da práxis educativa. Por outro lado, traz desafios à universidade e à escola, no que tange à valorização da corresponsabilidade da formação, no que diz respeito à busca por novos caminhos a serem trilhados para o exercício da cidadania.

Portanto, pode-se dizer que os atores participantes do programa puderam compreender que a formação de professor se dá em uma relação indissociável dos saberes teóricos e práticos e que também são construídos durante o percurso da formação pessoal e profissional, no chão e para além dos muros da escola. Sabendo que este processo de ser/estar professor não está pronto ou acabado, sendo, nesse contexto, fundamental que o professor continue estudando e se qualificando na área em que ensina.

Por fim, acreditamos na importância de inserir o futuro professor na escola e sua ação-reflexão-ação diante das problemáticas cotidianas desse ambiente, a fim de produzir conjuntamente com os professores supervisores práticas que favoreçam a aprendizagem significativa e, também, a construção da cultura da do-discência com o olhar para o contexto social. Aspectos esses que exigirão do futuro professor reflexão, estudos e análises dos problemas de como se aprende e de como se ensina.

\section{Referências}

ARAÚJO. M. L. F. A educação ambiental na formação de professores de ciências e biologia: ações do Pibid biologia da UFRPE. In: SILVA, A. R. et al. PIBID: reflexões teóricas e vivências formativas. Recife: Editora da UFRPE, 2017. p. 69-84.

BAIRD, J. R.; FENSHAM, P. J.; GUNSTONE, R. F.; WHITE, R. T. The importance of reflection in improving science teaching and learning. Journal of Research in Science Teaching, Hoboken, v. 28, n. 2, p. 163-182, 1991. DOI: https://doi.org/b6dcfk.

BARBOSA, S. M. C.; SOARES, J. R. A importância do Pibid no contexto da educação brasileira para a formação de professores no Brasil. In: SEMINÁRIO, 1. e ENCONTRO Pibid, 2., 2012, Campinas. Resumos [...]. Campinas: Unicamp, 2012. 
BARCELOS, N, N. S.; VILLANI, A. Troca entre universidade e escola na formação docente: uma experiência de formação inicial e continuada. Ciência \& Educação, Bauru, v. 12, n. 1, p. 73-97, 2006. DOI: https://doi.org/b5bv28.

BARDIN, L. Análise de conteúdo. São Paulo: Edições 70, 2011.

BEREZUK, P. A.; INADA, P. Avaliação dos laboratórios de ciências e biologia das escolas públicas e particulares de Maringá, estado do Paraná. Acta Scientiarum: human and social sciences, Maringá, v. 32, n. 2, p. 207-215, 2010. DOI: https://doi.org/bwk7bc.

BORGES, M. C.; DANTAS, S. M. Formação inicial e continuada no Pibid: interação entre professores e alunos da educação básica e superior. In: OLIVEIRA JÚNIOR, A. P.; ZEULLI E.; DANTAS, S. M. (org.). Interface entre teoria e prática na formação docente: reflexões sobre experiências no Pibid. São Carlos: Pedro \& João, 2015. p. 175-194.

BRASIL. Coordenação de Aperfeiçoamento de Pessoal de Nível Superior. Portaria CAPES no 260 de 30/12/2010. Aprova as normas do programa institucional de bolsa de iniciação à docência - Pibid. Disponível em: https://cutt.ly/vErEmXu. Acesso em: 1 mar. 2017.

CUNHA, A. M. O.; KRASILCHIK, M. A formação continuada de professores de ciências: percepções a partir de uma experiência. In: REUNIÃO ANUAL DA ANPED, 23., 2000, Caxambu, MG. Anais [...]. Caxambu: NAPED, 2000.

DANTAS, F. K. S.; FERNANDES, E. F.; SILVA, M. O.; SILVA, J. D. G. Formação continuada de professores de biologia em Iguatu/CE: concepções dos docentes sobre a relevância desses cursos. In: CONGRESSO NACIONAL DE EDUCAÇÃO, 3., 2016, Natal, RN. Disponível em: https://cutt. ly/OErRJys. Acesso em: 2 jul. 2018.

FELÍCIO, H. M. S. O PIBID como "terceiro espaço" de formação inicial de professores. Revista Diálogo Educacional, Curitiba, v. 14, n. 42, p. 415-434, 2014. DOI: https://doi.org/gv8z.

FRASER, M. T. D.; GONDIM, S. M. G. Da fala do outro ao texto negociado: discussões sobre a entrevista na pesquisa qualitativa. Paidéia, Ribeirão Preto, v. 14, n. 28, 2004. DOI: https://doi.org/ btd4c6.

FRISON, L. M. B.; LEITE, V. C.; BARCELLOS, C. S. R. Percurso de formação inicial e continuada: projetos interdisciplinares realizados no PIBID. Crítica Educativa, Sorocaba, v. 3, n. 2, 2017, p. 519532. Número especial. DOI: https://doi.org/gv83.

GARCIA, J. E.; PORLÁN, R. Ensino de ciências e prática docente: uma teoria do conhecimento profissional. Caderno Pedagógico, Lajeado, n. 3, p. 7-42, 2000.

GATTI, B. A. Análise das políticas públicas para formação continuada no Brasil, na última década. Revista Brasileira de Educação, Rio de Janeiro, v. 13, n. 37, p. 57-70, 2008. DOI: https://doi.org/ cnt2gd.

GIL, A. C. Metodologia do trabalho científico: métodos e técnicas da pesquisa. São Paulo: Cortez, 2002.

KRASILCHIK, M. O professor e o currículo das ciências. São Paulo: Edusp, 1987.

LÜCK, H. Pedagogia da interdisciplinaridade: fundamentos teórico-metodológicos. Petrópolis: Vozes, 2009.

LUCKESI, C. C. Avaliação da aprendizagem escolar: estudos e proposições. São Paulo: Cortez, 2002.

MALDANER, O. A. A formação inicial e continuada de professores de química. Ijuí: Editora Unijuí, 2000.

OLIVEIRA, M. M. Como fazer pesquisa qualitativa. 4. ed. Petrópolis: Vozes, 2012. 
PIMENTA, S. G.; LIMA, M. S. L. Estágio e docência: diferentes concepções. Revista Poíesis Pedagógica, Catalão, GO, v. 3, n. 3-4, p. 5-24, 2006. DOI: https://doi.org/gfxfxv.

RODRIGUES, F.; ARENA, D. B. Professores flexíveis às mudanças e professores que resistem a mudar: impacto da formação no trabalho com a leitura. In: CONGRESSO DE LEITURA, 6., 2007, Campinas. Anais [...] Campinas: Unicamp, 2007. p. 1-9.

SANTOS, M. Z. M. O PIBID e a formação continuada de professores de ciências biológicas: contribuições para a prática docente. 2016. 158 f. Dissertação (Mestrado em Educação em Ciências e Matemática) - Faculdade de Física, Pontifícia Universidade Católica do Rio Grande do Sul, Porto Alegre, 2016. Disponível em: https://cutt.ly/oErACH5. Acesso em: 6 jul. 2018.

SANTOS, M. Z. M.; SOARES, B. M.; SCHEID, N. M. J. O PIBID e a formação de professores de ciências biológicas da URI, Santo Ângelo, Brasil. Interações, Santarém, Portugal, v. 11, n. 39, p. 155-174, 2015. Número especial. DOI: https://doi.org/gv87.

SOARES, M. H. F. B. Jogos e atividades lúdicas para o ensino de química. Goiânia: Kelps, 2013.

TARDIF, M. Saberes docentes e formação profissional. Petrópolis: Vozes, 2007.

ZEICHNER, K. Repensando as conexões entre a formação na universidade e as experiências de campo na formação de professores em faculdades e universidades. Educação, Santa Maria, v. 35, n. 3, p 479-504, 2010. Disponível em: https://cutt.ly/TErDttd. Acesso em: 6 set. 2021. 